\title{
Cerebral Blood Flow in Patients with Intracranial Pressure Elevation due to Traumatic Brain Edema
}

\author{
W. A. TWEED AND J $\emptyset$ RN OVERGAARD
}

SUMMARY: The object of this study was to determine if traumatic brain edema $(B E)$ and increased intracranial pressure (ICP) reduce cerebral blood flow (CBF). Two groups of patients were studied, one with slight $B E$ and ICP less than $20 \mathrm{~mm} \mathrm{Hg}$., the other with pronounced $B E$ and ICP over 20 $\mathrm{mm} \mathrm{Hg}$. Although ICP was higher and cerebral perfusion pressure lower in pro-

RESUMÉ: Cette étude avait pour but de déterminer si l'oedème cérébral post traumatique et l'élévation de la pression intra-cranienne réduisent le débit sauguin cérébral. Pour ce faire, nous avons étudié 2 groupes de sujets, l'un oedème cérébral modéré et une pression intra-cranienne inférieure a 20 $\mathrm{mm} \mathrm{Hg}$; et l'ature, avec un oedème cérébral important et une pression intracranienne supérieure à $20 \mathrm{~mm} \mathrm{Hg}$. Quoique la pression intra-cranienne était plus élevé et la pression de perfusion diminuée dans le groupe avec nounced edema there was only a small and non-significant reduction in $C B F$ and no difference in cerebro-vascular resistance. Since traumatic $B E$ does not increase resistance to blood flow through the brain, cerebral perfusion can be maintained if an adequate perfusion pressure is established. This in turn, demands the monitoring and control of ICP.

oedème cérébral prononcé, nous n'avons noté qu'une diminution minime et non significative du débit sanguin cérébral. De plus, il n'y avait aucune différence au niveau des résistances cérébro-vasculaires. Puisque l'oedème cérébral post-traumatique n'augmen pas les résistances vasculaires cérébrales une pression de perfusion adéquate assurerait une perfusion cérébrale. Mais ceci implaique un monitoring et un controle de la pression intra-cranienne.
From the Department of Anesthesia, Health Sciences Centre (General), Winnipeg, Canada and Odense University Hospital, DK 5000, Odense, Denmark.

This work was done while Dr. Tweed was a Centennial Fellow of the Medical Research Council of Canada.

Reprint requests to Dr. W. A. Tweed, Department of Anaesthesia, Health Science Centre, 700 William Ave., Winnipeg, Canada. R3E 0Z3.
Although traumatic brain edema (BE) and increased intra-cranial pressure (ICP) are common complications of head injury, there are few studies of cerebral hemodynamics in patients with these complications. This is a report of clinical investigations in patients with ICP elevation and $\mathrm{BE}$ following severe closed head injuries. Twenty-six patients were studied within 14 days after injury, with measurements of cerebral blood flow (CBF), mean arterial blood pressure (MABP), mean intraventricular pressure (MIVP), and arterial blood gases.

\section{METHODS}

CBF was measured by the intracarotid xenon injection method, recording the washout of xenon from the brain with 35 externally located scintillation detectors (Meditronic Cerebrograph), arranged in an array over the ipsilateral cranium. The average hemispheric CBF was calculated by the initial slope method (Olesen et al., 1971) from the singlc washout curve that was obtained by continuously recording the average counting rate of the 35 separate channels. CBF derived by the initial slope method is designated CBF init. to distinguish it from other values for CBF which can be obtained by applying different analyses to the same washout curve. $\mathrm{CBF}$ init. is higher than the mean CBF calculated by the height over area method, and is closer to, but not identical with, grey matter flow in a normal brain. The advantage of using CBF init. in clinical studies is that it requires only two minutes of steady state recording while other methods require 10 minutes or more of recording time.

During each CBF measurement MABP was continuously recorded 


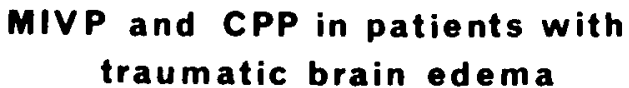

traumatic brain edema

\section{CBF and CVR in patients with \\ traumatic brain edema}

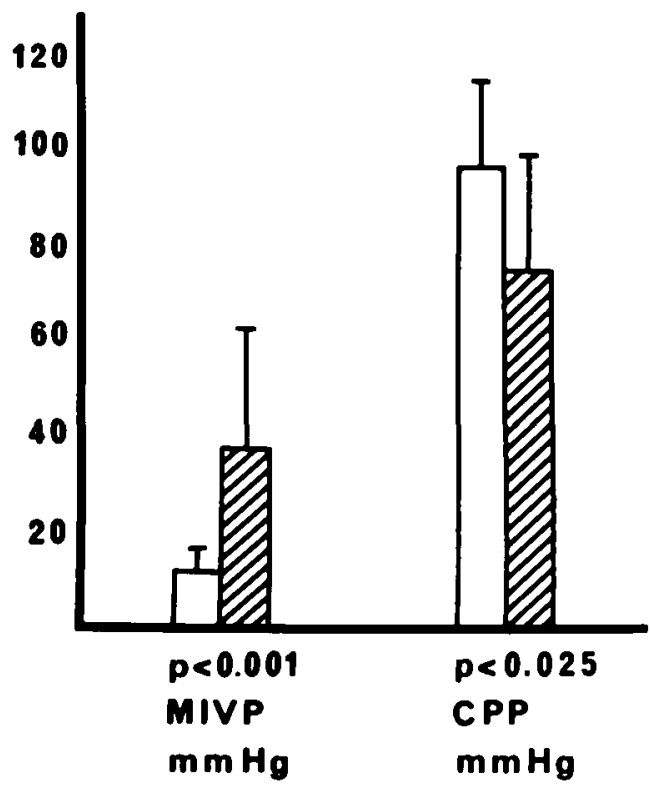

Figure l-Mean intraventricular pressure (MIVP) and cerebral perfusion pressure (CPP) in patients with traumatic brain edema.
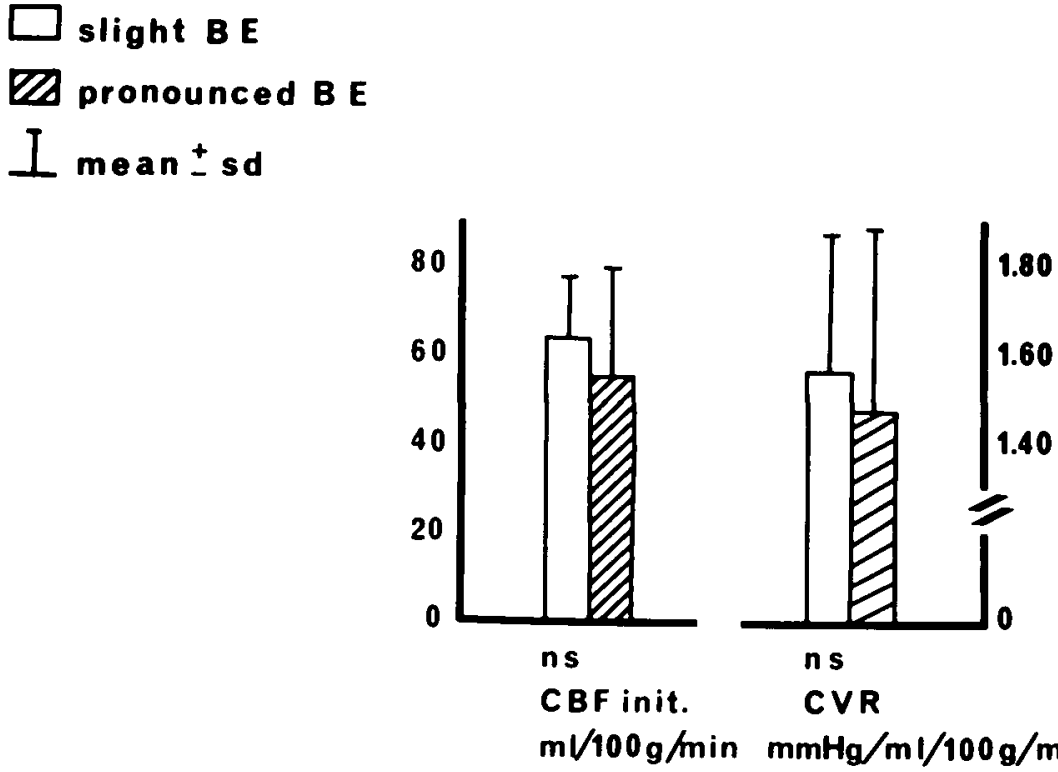

CVR

$\mathrm{mV} / 100 \mathrm{~g} / \mathrm{min} \mathrm{mmHg} / \mathrm{ml} / 100 \mathrm{~g} / \mathrm{min}$

Figure 2-Cerebral blood flow (CBF) and cerebrovascular resistance (CVR) in patients with traumatic brain edema. from the carotid artery catheter, and MIVP from a catheter inserted through a burrhole into a lateral cerebral ventricle. Cerebral perfusion pressure (CPP) was calculated as the difference between MABP and MIVP and cerebrovascular resistance (CVR) across the brain as $\mathrm{CPP} / \mathrm{CBF}$ init.

An anaerobic sample of arterial blood was taken after each xenon injection and analyzed in a radiometer gas analyzer for blood gases and acid-base.

The difficulty of estimating $\mathrm{BE}$ clinically is well known. We assessed $B E$ at each CBF examination by the following criteria:

1. angiographic and ventriculographic displacements not due to hematomas.

2. direct observation of brain swelling at operation when possible.

3. persistent elevation of MIVP over $20 \mathrm{~mm} \mathrm{Hg}$. during normocapnia, and after hematomas had been evacuated.

Although the first two criteria may give a qualitative estimate of $\mathrm{BE}$, it was only possible to rank edema quantitatively by its effects on
MIVP. Since all hematomas were evacuated before MIVP monitoring began, persistent elevation of MIVP in the acute phase after injury was considered indicative of $\mathrm{BE}$. (Later elevation of MIVP may be due to post-traumatic hydrocephalus). Since we could not be certain that any patient had no BE we have classified them as slight edema (MIVP less than $20 \mathrm{~mm}$. $\mathrm{Hg}$. with the first and second criteria negative), or prenounced edema (MIVP over 20 $\mathrm{mm}$. Hg. plus criteria 1 or 2). CBF was always measured in the hemisphere with the most evident edema.

\section{RESULTS}

The results in patients with slight and pronounced $\mathrm{BE}$ are illustrated in figures $1 / 2$. There was no difference in neurological status between the groups, and only a small difference in $\mathrm{PCO}_{2}, 38.9 \pm 6.1$ in the slight edema group versus $36.6 \pm 8.1$ in the group with pronounced edema. The significance of the differences between the two groups was tested by the unpaired t-test.

MIVP was significantly higher and as a consequence CPP was lower in the group with pronounced edema. However, there was only a small and non-significant reduction in $\mathrm{CBF}$ init. which was due to the reduction in perfusion pressure since calculated CVR was not significantly different (actually slightly less) in pronounced edema. Calculated CVR did not show any consistent relationship to the severity of edema or the level of MIVP; that is, CVR was not higher in those with more pronounced edema.

\section{DISCUSSION}

CBF init., calculated from the initial slope of the xenon washout curve, is a measure of perfusion in the high flow tissues of the brain. In the normal brain, CBF init. correlates most closely with flow-grey (Olesen et al., 1971), and we consider that in clinical studies it primarily indicates cortical flow. It is linearly related to, but higher than, the mean flow calculated by the ten minute height over area method (Overgaard and Tweed, 1974). MIVP has been shown by others to approximate very closely subarachnoid venous pressure (Rowan et al., 
1972). Therefore CVR as we calculate it (CVR $=\mathrm{CPP} / \mathrm{CBF}$ init.) represents the resistance to flow from the internal carotid artery through the cerebral cortices to the subarachnoid veins.

Studies by Bruce et al. (1973) suggest that resistance to blood flow is increased through edematous brain tissue. Our studies do not support, but do not entirely disprove, their conclusions. Although we have found no evidence of an increased resistance to flow in the presence of brain edema, it may be that we are not measuring flow through the actual edematous tissue. The initial slope method measures primarily cortical flow and edema is found primarily in white matter (Feigin and Popoff, 1962). We may therefore be measuring flow in cortical tissue that is not itself edematous but is affected by vasodilator metabolites, for example, lactic acid, diffusing from adjacent edematous white matter. We might, on the other hand, postulate that the resistance to flow at the microcirculatory level is increased in edematous brain tissue, but that this increase in resistance is more than offset by a reduction of resistance due to vasodilation in more proximal components of the vascular system, that is the resistance arteries. This would occur if the autoregulation of $\mathrm{CBF}$ was wholly or partially intact.

In this clinical study of BE we have not observed a significant increase in CVR across the brain with increasing severity of $\mathrm{BE}$. This suggests that severe traumatic $B E$ can be likened to an expanding intracranial mass lesion that increases the volume of the intracranial contents and elevates ICP. Since subarachnoid venous pressure closely follows
ICP, resistance to flow will increase at the level of the subarachnoid veins and CPP will be reduced. Compressive or obstructive effects on the tissue microcirculation appear to be of minor importance. This discussion applies only to traumatic $\mathrm{BE}$ and in other cases, for example focal cortical lesions or peri-focal tumor edema, the pathophysiology may be different.

The logical conclusion from these studies is that cerebral perfusion can be maintained in the post traumatic state, even in the presence of $\mathrm{BE}$, if an adequate perfusion pressure (CPP) can be established. This in turn requires continuous monitoring of ICP, and vigorous treatment of elevated ICP. On the other hand, attempts to maintain CPP by artificial elevation of systemic blood pressure are likely to prove disastrous, leading to a vicious circle of increasing edema and rising ICP. There is good experimental evidence that systemic hypertension promotes the formation and spread of $\mathrm{BE}$ in the injured brain (Klatzo, 1972; Marshal et al., 1969; Meinig et al., 1972). We have also shown in clinical studies that when ICP is elevated and the autoregulatory control of $\mathrm{CBF}$ is lost, systemic hypertension provokes an immediate further rise in ICP, due to both passive vasocongestion and increased edema formation (Tweed and Overgaard, 1975). This evidence suggests also that the episodic spontaneous hypertension, commonly observed in brain injured patients, is deleterious. In order to break this vicious cycle we propose that it is necessary not only to prevent episodic hypertension (with phenobarbital), but also to control ICP to less than $20 \mathrm{~mm} \mathrm{Hg}$. At this level passive changes of ICP with changes in blood pressure are not observed (Tweed and Overgaard, 1975), and CBF is adequate to satisfy the nutritional requirements of the brain.

\section{REFERENCES}

BRUCE, D. A., LANGFITT, T. W., MILLER, J. D., SCHUTZ, H., VAPALAHTI, M. P., STANEK, A., GOLDBERG, I. H. (1973). Regional cerebral blood flow, intracranial pressure, and brain metabolism in comatose patients. J. Neurosurg. 38, 131-144.

FEIGIN, L., POPOFF, N. (1962). Neuropathological observations on cerebral edema. Arch. Neurol. 6, 151-160.

KLATZO, 1. "Pathophysiological aspects of brain edema." In: Steroids and Brain Edema. H. J. Reulen and K. Schürmann, eds., New york: Springer Verlag (1972).

MARSHALL, W. J. S., JACKSON, J. L. F., and LANGFITT, T. W. (1969). Brain swelling caused by trauma and arterial hypertension: hemodynamic aspects. Arch. Neurol. 21, 545-553.

MEINIG, G., REULEN, H. J., HADJIDIMOS, A., SIEMON, C., BARTHO. D., and SCHURMANN, K. (1972). Induction of filtration edema by extreme reduction of cerebrovascular resistance associated with hypertension. European Neurol. 8, 97-103.

OLESEN, J., PAULSON, O. B. and LASSEN, N. A. (1971). Regional cerebral blood flow in man determined by the initial slope of the clearance of intra-arterially injected 133 Xe. Stroke 2, 519-540.

OVERGAARD, JORN, TWEED, W. A. (1974). Cerebral circulation after head injury: Part I. J. Neurosurg. 41, 531-541.

ROWAN, J. O., JOHNSTON, I. H., HARPER, A. M. and JENNET, W. B. Perfusion pressure in intracranial hypertension. In Intracranial Pressure, Edited by $M$. Brock and H. Dietz, Springer Verlag, 1972, Page 165.

TWEED, W. A. and OVERGAARD, J. Disturbed regulation of CBF after acute brain injury with particular reference to the effects on MIVP and CPP. In Cerebral Circulation and Metabolism, Edited by Thomas W. Langfitt, Lawrence C. McHenry, Jr., Martin Reivich and Harry Wollman, Springer-Verlag, 1975. Page 249. 